\title{
Os fundamentos transcendentais da daseinsanalyse psiquiátrica de Ludwig Binswanger
}

Rodrigo Alvarenga*1

Ludwig Binswanger compreendeu que era necessário reestruturar o método de investigação e abordagem dos fenômenos psicóticos, pelo afastamento da ontologia cartesiana do sujeito e do objeto, o qual pressupunha o dualismo e o solipsismo da consciência, para fundar uma abordagem intersubjetiva da psiquiatria. $O$ objetivo desta pesquisa é justamente examinar esse percurso fenomenológico da Daseinsanalyse psiquiátrica de Ludwig Binswanger, no que se refere ao cumprimento daquilo para o qual ela própria se propôs, por meio da assimilação da investigação transcendental no campo das psicoses.

Palavras-chave: Alteridade, fenomenologia, psiquiatria, psicose

\footnotetext{
${ }^{* 1}$ Pontifícia Universidade Católica do Paraná - PUC-PR (Curitiba, PR, Br).
} 


\section{OBSERVANDO A PSIQUIATRIA}

\section{Introdução}

Para Binswanger, a fenomenologia de Husserl e Heidegger poderia levar à superação daquilo que o psiquiatra considerava o grande problema de sua ciência, justamente a aplicação do método das ciências naturais, com base na ontologia da res cogitans e da res extensa. Apoiado no método fenomenológico e aplicando-o à psiquiatria, Binswanger propunha a renúncia de uma abordagem sobre a loucura que em seu afã de objetividade comprometesse o reconhecimento da alteridade. Seu objetivo inicial era dar lugar à perspectiva intuitiva, de inspiração husserliana, a fim de ultrapassar a lógica exclusivamente objetiva das ciências naturais. O psiquiatra estava interessado em uma investigação que pudesse desconstruir os edifícios epistemológicos da modernidade, e todo seu prejuízo para o campo das ciências sobre o humano, no sentido de uma visão objetiva que condiciona outrem à lógica de saberes positivos.

A Daseinsanalyse psiquiátrica, principalmente em sua última fase, aquela de Melancolia e Mania e Delírio, em que Binswanger se volta para a fenomenologia genética de Husserl, investiga as psicoses na perspectiva transcendental da gênese constitutiva do ego e do alter ego, bem como do alter ego psicótico. Dessa forma, o objetivo central deste trabalho consiste justamente em analisar o desenvolvimento da fenomenologia das psicoses de Binswanger, em sua busca por uma abordagem mais ética do ponto de vista do reconhecimento da alteridade. ${ }^{1}$

\footnotetext{
${ }^{1}$ A avaliação crítica da relação entre psiquiatria e fenomenologia nos moldes articulados por Ludwig Binswanger, bem como a efetividade de seu alcance ético serão avaliados em outro trabalho, o qual será publicado em breve. Por enquanto, cabe apenas salientar a existência de uma grande discussão sobre a validade dessa aproximação entre o campo transcendental e empírico no desenvolvimento da Daseinsanalyse psiquiátrica, conforme indicou o próprio Heidegger (2009) nos Seminários de Zollikon e alguns de seus principais comentadores no Brasil, como Loparic (2002) e Pita \& Moreira (2013).
} 


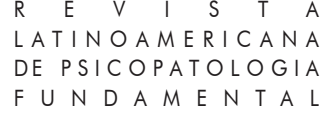

A questão é analisar como temporalidade e a estrutura funcional da intencionalidade, conforme elaborada por Husserl, foi utilizada por Binswanger como um modo de compreender as psicoses e fundar uma prática psiquiátrica. Para esse fim, se faz necessário investigar o desenvolvimento fenomenológico existencial das bases da Daseinsanalyse psiquiátrica, desde a sua primeira estruturação, em termos de uma eidética dos estados psicóticos, passando pela fase ontológica, em que a influência de Heidegger é mais evidente, até o retorno a Husserl e a tipificação das psicoses nos moldes da gênese constitutiva da temporalidade.

\section{Husserl e a descrição da essência do mundo psicótico}

Por meio da fenomenologia descritiva de Husserl, Binswanger se aproximou do pensamento fenomenológico e passou a questionar o naturalismo das abordagens científicas e psicanalíticas. O propósito de Husserl estava relacionado justamente à criação de uma nova abordagem para a ciência, em especial para a psicologia, por meio do aprofundamento do conceito de intencionalidade de Franz Brentano. Como afirma Husserl em "A crise das ciências

370 europeias e a fenomenologia transcendental", a origem desse problema diz respeito àquela ingenuidade da ciência de tomar "o mundo objetivo pelo universo de todo o ser, sem com isso atentar que a subjetividade operante na ciência não pode, por direito, comparecer em nenhuma ciência objetiva" (Husserl, 1913/2012, p. 272).

Ao excluir a subjetividade do campo da investigação científica, coube à psicologia o estudo do psíquico, porém tal estudo se deu por meio da abordagem dualista, a qual pensa o psíquico em sua relação com o fisiológico, de modo a ignorar a camada da existência que serve como a condição de possibilidade da própria dicotomia. Trata-se de algo não considerado pelo investigador da natureza, mas que é "constantemente pressuposto como solo, como esse campo de trabalho unicamente pelo qual têm sentido as suas perguntas e os seus métodos de pensamento" (Husserl, 1913/2012, p. 271).

Dessa forma, seria importante para a psicologia não apenas investigar o psiquismo em sua correspondência com os processos empíricos e entidades reais, mas compreender também essa dimensão do psíquico que não é o resultado da atividade intelectiva da consciência, mas uma realidade que está sempre pressuposta em seus atos. Conforme a análise de MüllerGranzotto, \& Müller-Granzotto (2007), "pela escrita de Husserl, a ficção ultrapassou a condição de recurso estilístico para se tornar a forma apropriada 


\section{OBSERVANDO A PSIQUIATRIA}

de apresentação de nossa ligação com o mundo e com o semelhante" (p. 50). A fenomenologia, enquanto Wesenforschung, tornou-se interessante para a psiquiatria, justamente por permitir uma alternativa ao naturalismo, pela ressignificação da atitude natural.

Segundo Binswanger (1947/1971), a fenomenologia permitiria ao psiquiatra atentar para a maneira como as palavras se apresentam em um discurso delirante, de modo a possibilitar não apenas a deteç̧ão de equívocos semânticos e suas dessemelhanças com o discurso normal, mas viabilizar a compreensão de um sentido mais profundo no relato do consulente. Contudo, descrever a essência dos mundos psicóticos não permitia a Binswanger compreender os aspectos existenciais desses mundos; assim, seria necessário buscar na analítica do dasein de Heidegger uma explicação na perspectiva do ser no mundo para os diferentes estados delirantes e alucinatórios.

\section{Heidegger e as estruturas existenciais do mundo psicótico}

$\mathrm{O}$ interesse do psiquiatra pela analítica existencial do dasein surge dos limites encontrados na fenomenologia descritiva do primeiro Husserl, quanto às possibilidades de compreensão das modificações psiquiátricas em sua amplitude, sendo necessário o alargamento da noção de intencionalidade, a fim de melhor compreender a diversidade dos mundos constituídos na psicopatologia. Segundo Heidegger (1927/2012), “o que se busca é responder a questão do sentido do ser em geral e, antes disso, a possibilidade de elaborar radicalmente essa questão fundamental de toda ontologia” (p. 303). É justamente em razão de a analítica existencial visar compreender esse campo ou dimensão do ser que se revela como fundamento de toda e qualquer ontologia regional que Binswanger e a psiquiatria irão se interessar por Ser e tempo. Mais especificamente, na medida em que o dasein se caracteriza pelas estruturas existenciais ser-no-mundo, espacialidade, temporalidade, ser-com, ser-para-morte, os estados psicóticos poderiam ser compreendidos a partir dessas perspectivas. Isso no sentido de que "o psicótico, mesmo o mais atingido pela psicose, não pode não estar no tempo, no espaço, na corporeidade, na relação com os outros; mas a patologia pode alterar, distorcer, bloquear suas coordenadas existenciais" (Chamond, 2011, p. 5).

Essa busca de Binswanger pela analítica existencial de Heidegger se evidencia a partir de 1930 com a publicação de $O$ sonho e a existência. Ao analisar o fenômeno da invasão de um elemento estrangeiro em meio à existência cotidiana, que se manifesta pela experiência de uma queda livre como 


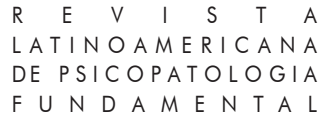

se não houvesse mais nenhum apoio para sustentar o drama insuperável e, muitas vezes, insuportável da existência, o texto de 1930 ilustra exatamente a forma como a perspectiva heideggeriana se faz presente. Tratando da experiência de queda, no sentido de uma decepção que desestabiliza a pessoa, Binswanger demonstra como a espacialidade, estrutura existencial do dasein, pauta a forma de expressão linguística, quando no sofrimento por um fato desconcertante e inesperado.

De acordo com Binswanger (1947/1971), em vivências relacionadas a grandes decepções, a linguagem "vai, espontaneamente, recolher, nessa pretensa comparação, um traço essencial, específico da estrutura ontológica do ser humano, ou seja, o poder dirigir-se de alto para baixo, descrevendo-o, consequentemente, como uma queda" (p. 223). Dessa forma, isso que pode acometer a pessoa em determinadas fases da vida seria uma característica essencial da psicopatologia, como se o consulente psiquiátrico tivesse sua existência deslocada na experiência de arrebatamento ou de queda, sem encontrar condições que permitissem sua reestruturação psíquica como um ego. A expressão em questão seria "eu não sei o que me está acontecendo" (p. 224).

Em o Sonho e a existência Binswanger analisa a questão da espacialidade a partir do pensamento de Heráclito, tendo em vista a distinção entre a vida individual e o mundo comum, a fim de tentar explicar essa experiência que não é elaborada pelo indivíduo, mas que o possui durante o sono, a saber, o sonho. Há, nesse sentido, uma forma individual de existência, marcada pela dispersão (idios) e outra forma coletiva caracterizada pela união (koinos), sendo a experiência do sono e do sonho uma espécie de passagem para outra realidade na qual o mundo comum se esvazia de sentido para dar lugar à experiência do mundo solipsista. A vigília seria a saída desse lugar que se constitui como experiência privada de pensamento, em que o contato com a totalidade, com o mundo e com outrem encontra-se comprometido. Despertar de um sonho é como sair da esfera do idion Kosmos (mundo privado), para entrar na dimensão do koinos Kosmos (mundo comum), esfera do universal (Binswanger, 1947/1971).

Assim, a psicoterapia corresponderia a um percurso que o consulente teria que trilhar, sob a condução do médico, para libertar-se do isolamento e das ilusões decorrentes do rompimento nas relações com o mundo e com outrem. Inspirado pela obra $E u$ e $t u$, de seu contemporâneo Martin Buber, o psiquiatra procurou desenvolver a teoria do cuidado (Sorge) de Heidegger, por 


\section{OBSERVANDO A PSIQUIATRIA}

meio da noção de Wirheit. ${ }^{2}$ Revelando uma análise profunda e detalhada de Ser e tempo, a obra de 1492 irá se distanciando de Heidegger na medida em que explora não mais a finitude do ser-para-a-morte, mas a infinitude do amor, não mais a ipseidade do ser que se desloca no tempo, mas a anterioridade do Wirheit em relação à perspectiva do ego e do alter ego.

A questão para Binswanger é que a noção de cuidado em Heidegger, enquanto elemento existencial próprio do ser do Dasein, é condicionada pela perspectiva temporal do ser-para-morte, contudo, o amor está fora ou transcende essa perspectiva. De acordo com Binswanger (1993a), o ser-um-comoutro antecede a experiência de ser-para-morte, o que significa que o Dasein não poderia ter como sua estrutura mais fundamental o cuidado, uma vez que ele está condicionado à temporalidade.

Antes de pensar o Dasein como poder-ser enquanto cuidado, portanto uma ipseidade que se desenrola no tempo, é preciso pensá-lo como poderser-um-com-outro, como noustrité que se eterniza. Como explica Coulomb (2009), fazer do cuidado o aspecto mais essencial do ser-no-mundo é considerar que a preocupação e a utilização antecedem o ser-com-outro. Na época em que Binswanger volta-se sobre o Ser e tempo de Heidegger, seu interesse maior estava na possibilidade de dar respostas aos problemas concretos que se colocam ao psiquiatra, que se referem à historicidade dos sujeitos psicóticos. Tratava-se, portanto, de "retirar a psicopatia esquizoide e a esquizofrenia do quadro estreito do juízo de valor biológico - como deve ser considerado o juízo médico - e do estado de coisas médico psiquiátrico da doença e da morbidez" (Binswanger, 1985, p. 11).

Seu interesse estava focado em analisar a esquizofrenia no "quadro mais amplo da estrutura existencial ou do ser-no-mundo humano, cujo a priori foi 'trazido à luz' por Heidegger em sua analítica existencial”' (p. 11). Contudo,

${ }^{2}$ Wirheit é um termo alemão de difícil tradução, que na língua francesa é traduzido como noustrité e em português não há termo correspondente, talvez possamos utilizar a expressão nostridade, para explicar esse aspecto do Dasein, que para além do 'ser-aí', significa 'ser-umcom-outro, a forma existencial do mundo comum, da identidade do nós como fundante do ego (Cabestan \& Dastur, 2011). De acordo com Binswanger (1993a), a noção de Wirheit é utilizada como um modo de "demonstrar como eu-mesmo e tu-mesmo - no sentido do amor — podemos ser, sem que Nós - no sentido do amor — cesse de ser” (p. 110). Seria justamente essa possibilidade que estaria comprometida das psicoses, em função do “"estrangulamento' ou 'declínio' do ser-um-com-outro degradado em simples ser-com 'de um e de um outro'” (Binswanger, 1993a, p. 10). 


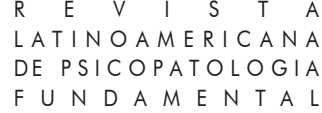

não bastava para a psiquiatria enquanto ciência a ideia de que se tratavam de distúrbios relacionados a dificuldades na transição entre o mundo próprio e o mundo comum, ocasionados por modificações nas estruturas existenciais do Dasein humano. Seria necessário compreender de que modo essas estruturas foram alteradas. Segundo Naudin (1997), "se a linguagem heideggeriana convém bem à compreensão fática e biográfica do delírio, ela não permite, talvez, uma melhor compreensão de sua gênese" (p. 20).

Sendo assim, passou a interessar a Binswanger saber quais os possíveis tipos de distúrbios psicóticos, de acordo com as características transcendentais que os fundamenta, o que seria encontrado na filosofia genética de Husserl, principalmente após a leitura da obra Introdução à fenomenologia de Husserl (1959/1973), do filósofo e amigo Wilhelm Szilasi, na qual a questão da intersubjetividade e da gênese constitutiva do ego transcendental são trabalhadas (Szilazi, 1959/1973).

\section{O retorno a Husserl e a gênese das formações psicóticas}

Binswanger faz um caminho que vai da antropologia revelada pela investigação das estruturas existenciais do Dasein humano, até a busca das características transcendentais fundamentais de cada mundo psicótico, enquanto temporalidade. O psiquiatra vai procurar investigar a partir da fenomenologia genética de Husserl "quais são as operações (Leistungen) transcendentais falhadas - ou seja, qual é a modalidade de vida 'vivente' que os mundos maníacos e melancólicos edificam?” (Tatossian, 1979/2006, p. 156). Na obra Melancolia e mania se evidencia o resultado desse interesse, quando se procura descrever as vivências temporais típicas dos mundos alterados, a fim de conhecer "a constituição desses mundos, como do Ego que aparece aí ou de Outrem que aí é encontrado" (p. 157).

Trata-se de compreender a psicopatologia a partir de uma investigação transcendental, ou seja, considerando o fenômeno da correlação entre a vivência empírica do sujeito na psicose e o aspecto transcendental de sua condição de possibilidade. Trata-se de "reenviar (ruckweiss) cada 'objetividade' constituída a uma forma essencial correlativa de intencionalidade, isso que é para ela a forma constitutiva" (Binswanger, 1960/1987, p. 23). A dificuldade do consulente em transitar de seu mundo próprio para o mundo comum, e os delírios e alucinações associados a essa impossibilidade serão interpretados a partir das alterações no fluxo temporal da consciência. 


\section{OBSERVANDO A PSIQUIATRIA}

O problema estaria no modo como, pela intencionalidade, articulam-se as vivências temporais pré-reflexivas do passado, presente e futuro, aquelas vivências que fornecem o sentido da experiência do tempo como duração e a possibilidade do mundo e de outrem serem apresentados à consciência como fenômenos que duram. No caso da retrospecção melancólica, por exemplo, em que o consulente lamenta-se constantemente sobre os atos do passado e suas consequências para o presente, o que se revela é justamente uma interrupção no fluxo da consciência. Segundo Binswanger (1960/1987), o melancólico não consegue se desvencilhar do passado e tem, por consequência, a perspectiva sobre o futuro interrompida, fazendo com que o seu presente seja vazio de significação.

Por outro lado, há também a prospecção melancólica nos casos em que a fixação não está no passado, mas no futuro, como quando o consulente assume uma postura extremamente pessimista sobre o porvir, não como possibilidade de que algo vai dar errado, mas como certeza do fracasso. É como se na vivência empírica o sujeito manifestasse o desequilíbrio relacionado à esfera transcendental, fazendo com que o delírio melancólico ou maníaco fosse uma resposta à desestruturação do ego.

O problema que se manifesta empiricamente como distúrbio está relacionado à gênese constitutiva do tempo e, por consequência do ego e do alter ego, no sentido de uma espécie de mistura entre as retenções e protensões, como se houvesse a infiltração de um horizonte temporal no outro. ${ }^{3}$ Por consequência, busca-se compensar empiricamente aquilo que se encontra desajustado, de modo que o sujeito vive seu delírio retrospectivamente ou prospectivamente, fixando-se no passado ou no futuro. Em se tratando dos comportamentos maníacos não é o 'relaxamento' da 'trama' temporal no sentido da confusão

\footnotetext{
${ }^{3}$ É o fenômeno da retenção que tornará possível para a consciência perceber a duração, visto que as sínteses intelectuais que caracterizam os modos de escoamento e retomada do passado se apresentam como virtualidades possíveis em face do instante atual. Cada instante que se tornou antigo mantém um vínculo com a atualidade do tempo presente, no sentido de um escoamento que, por mais longínqua que seja sua ligação com a atualidade da situação, permanece de algum modo como presente. Isso significa que cada instante vivido não desaparece com a emergência do instante seguinte, mas se doa como perfil ao instante ulterior, constituindo uma 'calda de cometa de retenções'. Conforme Husserl (1983), toda percepção se caracteriza por uma espécie de protoimpressão, a qual, por sua vez, se define como um continuum retencional, pois cada ponto posterior é retenção para o ponto anterior. Eis, justamente, o que possibilitará também a projeção de um horizonte temporal futuro, pois o fluxo temporal se projeta de forma contínua para além do último agora atual, constituindo um horizonte de protensões, uma espécie de projeção imaginária do fundo de retenções que possibilita o sentido de futuro.
} 


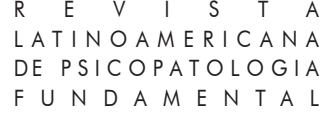

entre as retenções e as protensões que se evidencia, mas o seu desaparecimento. É o próprio ego transcendental que não se constituiu, fazendo com que os estados maníacos se concentrem na momentaneidade do tempo presente, comprometendo de forma mais radical a relação com outrem. Retomando as Meditações metafísicas de Husserl, o psiquiatra ressalta a importância dessa discussão para a compreensão do delírio maníaco e considera que a teoria da intersubjetividade de Husserl é essencial para descrever o sentido da perda da vida comum pelo consulente (Binswanger, 1960/1987).

Como explica Tatossian (1979/2006), o ponto de partida na análise constitutiva da mania não é a temporalidade, pois embora haja relaxamento nas relações entre retenção e protensão, diferentemente do delírio melancólico, não ocorre a infiltração de uma dimensão temporal sobre a outra, ou seja, não há retessitura confusa da temporalidade. Dessa forma, a intersubjetividade não está totalmente comprometida na melancolia, uma vez que a temporalidade continua operando na constituição do alter ego, ainda que de forma equivocada. Por outro lado, na mania, pelo fato de a própria constituição do horizonte temporal não estar ocorrendo e a existência estar limitada ao instante presente, a apresentação de outrem para a consciência praticamente

376 não acontece, o que irá impossibilitar o compartilhamento de uma existência comum nos estados maníacos.

\section{Considerações finais}

A experiência vivida nos casos analisados por Binswanger, conforme a própria narrativa dos consulentes, manifesta-se como se a pessoa fosse tomada por uma força estranha que invade e tira do centro o papel preponderante de sua subjetividade. Os próprios pensamentos parecem não ter sido produzidos por si mesmo, mas por outrem, pelo motivo de o ego não se apresentar de forma autêntica, por consequência, nem o mundo e nem o alter ego. Assim, o desajustamento do fluxo temporal que caracteriza as vivências intencionais da consciência, a partir de seus momentos de retenção, apresentação e protensão, faz com que o consulente experimente sua própria consciência como the sendo estranha, visto ser o próprio ego transcendental que não se constitui na sua integralidade.

No caso de Aline, por exemplo, Binswanger (1965/1993b) analisa como a psicopatologia faz com que ela se fixe em expressões carregadas de elementos de posse. Os enunciados de suas expressões linguísticas remetem 


\section{OBSERVANDO A PSIQUIATRIA}

constantemente às formas: eu, meu e a mim. Trata-se de um tipo de comportamento que faz com que Aline relacione todos os fatos e acontecimentos à sua volta, bem como tudo aquilo que as pessoas dizem, à sua própria existência, como se o universo todo girasse em torno dela, e o que é pior no delírio, contra ela. Essa proximidade entre todos os acontecimentos e seu próprio ego significa, em certo sentido, o pertencimento de Aline ao mundo inteiro, o que se constitui como uma experiência aterrorizante, uma vez que lhe falta a percepção de si mesma como unidade temporal autônoma. Para Binswanger, a não apresentação do eu penso, em um sentido kantiano, ou do ego transcendental de Husserl, é o que torna a experiência confusa do mundo e de outrem.

O que se nota em Aline, de acordo com Binswanger (1965/1993b), é um modo de existir, ou uma 'forma existencial do Dasein', na qual a vivência do 'nós' não se apresenta em momento algum, visto que ela depende necessariamente do ego e do alter ego plenamente constituídos. A consulente é incapaz de experimentar o significado da expressão nós porque ela não consegue estabelecer os limites entre sua própria consciência, o mundo, e outrem, portanto, a experiência do 'nós' será sempre uma experiência estranha. Na verdade, ela nunca se refere a alguma experiência nesse sentido. Seu modo de constituir a relação entre o mundo privado de sua consciência e a esfera comum da existência se dá por meio de delírios de conexões telepáticas, mediúnicas ou magnéticas, o que revela justamente o comprometimento da unidade egoica. Desse modo, a percepção de outrem estará distorcida, pois a constituição da experiência do mundo unitário, ou seja, a constituição da unidade do ego encontra-se interrompida em maior ou menor grau, fazendo com que Aline não distinga com precisão o mundo interior e o mundo exterior.

Essa abordagem da Daseinsanalyse psiquiátrica de Binswanger se apresenta como algo bastante interessante do ponto de vista da intersubjetividade, aparentemente muito à frente das abordagens naturalistas que deram origem a uma ciência sobre a loucura, mesmo nos moldes da psicanálise freudiana. Isso porque em vez de tentar interpretar o fenômeno psicótico a partir do que ele significaria em si mesmo enquanto objeto de investigação, o psiquiatra foca na busca pelo sentido da perda da experiência intersubjetiva, preocupando-se em como tornar possível o retorno do transitivismo entre mundo próprio e mundo comum. Contudo, a validade teórica e o alcance ético da Daseinsanalyse psiquiátrica ainda encontram-se em discussão. 


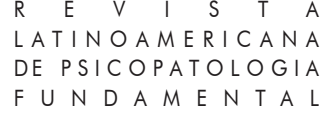

\section{Referências}

Binswanger, L. (1971). Introduction a l'analyse existentielle (J. Verdeaux, \& R. Kuhn, Trad.). Paris: Minuit. (Trabalho original publicado em 1947)

Binswanger, L. (1985). As três formas da existência malograda. Rio de Janeiro, RJ: Zahar.

Binswanger, L. (1987). Mélancolie e manie: études phénoménologique (J. M. Azorin, \& Y. Totoyan, Trad.). Paris: Presses Universitaires de France. (Trabalho original publicado em 1960).

Binswanger, L. (1993a). Grundformen und Erkenntnis maschlichen Daseins. Hamburgo: Asanger.

Binswanger, L. (1993b). Délire. (J. M. Azorin, \& Y. Totoyan, Trad.). Grenoble: Jérôme Millon (Trabalho original publicado em 1965).

Cabestan, P., \& Dastur, F. (2011). Daseinsanalyse. Paris: J. Vrin.

Chamond, J. (2011). Fenomenologia e psicopatologia do espaço vivido segundo Ludwig Binswanger: uma introdução. Revista da Abordagem Gestáltica, 17(1), 3-7. Recuperado de <http://pepsic.bvsalud.org/scielo.php?script=sci_ arttext\&pid $=$ S180968672011000100002\&lng $=$ pt\&tlng $=$ pt $>$.

Coulomb, M. (2009). Phénoménologie du Nous et psychopathologie de l'isolement. La nostrité selon Binswanger. Le Cercle Herméneutique, 11-12.

Heidegger, M. (2009). Seminários de Zollikon (G. Arnhold \& M. F. A. Prado, Trad.) Petrópolis, RJ: Vozes. Coleção Pensamento Humano. (Obra original publicada em 1987).

Heidegger, M. (2012). Ser e tempo (M. S. C. Schuback, Trad., $6^{\mathrm{a}}$ ed.). Petrópolis, RJ: Vozes. (Obra original publicada em 1927).

Husserl, E. (2012). A crise das ciências europeias e a fenomenologia transcendental (D. F. Ferrer, Trad.). Rio de Janeiro, RJ: Forense Universitária. (Obra original publicada em 1913).

Husserl, E. (1983). Leçons pour une phénoménologie de la conscience intime du temps (Henri Dussort, Trad.). Paris: Presses Universitaires de France.

Loparic, Z. (2002). Binswanger, leitor de Heidegger: um equívoco produtivo?. Natureza humana, 4(2), 383-413. Recuperado de $<$ http://pepsic.bvsalud.org/scielo. php?script=sci_arttext\&pid=S1517-24302002000200006\&lng=pt\&tlng=pt $>$.

Müller-Granzotto, M. J., \& Müller-Granzotto, R. L. (2007). Fenomenologia e GestaltTerapia. São Paulo: Summus.

Naudin, J. (1997). Phénoménologie et psychiatrie: les voix e la chose. Toulouse: Presses universitaires du Mirail. 


\section{OBSERVANDO A PSIQUIATRIA}

Pita, J., \& Moreira, V. (2013). As fases do pensamento fenomenológico de Ludwig Binswanger. Psicologia em Estudo, 18(4), 679-687. Recuperado de $<\mathrm{http}: / / \mathrm{www}$. scielo.br/pdf/pe/v18n4/10.pdf $>$.

Szilazi, W. (1973). Introducctión a la fenomenología de Husserl (R. Maliandi, Trad.). Buenos Aires: Amorrortu. (Obra original publicada em 1959).

Tatossian, A. (2006). A fenomenologia das psicoses (J. C. Freire, Trad. \& V. Moreira, rev. Tec.). São Paulo: Escuta. (Original publicado em 1979).

\section{Resumos}

(The transcendental foundations of the psychiatric Daseinsanalyse by Ludwig Binswanger)

Ludwig Binswanger understood that it was necessary to restructure the investigation method and the approach to psychotic phenomena, by detaching the Cartesian ontology from subject and object, which presumed the duality and the solipsism of consciousness in order to create an inter-subjective approach to psychiatry. The aim of this research is precisely to examine this phenomenological path of Ludwig Binswanger's psychiatric Daseinsanalyse, regarding the accomplishment of what it has proposed, by means of assimilating the transcendental investigation in the field of psychoses.

Key words: Otherness, phenomenology, psychiatry, psychosis

(Les fondements transcendantaux de la Daseinsanalyse psychiatrique chez Ludwig Binswanger)

Ludwig Binswanger a compris qu'il fallait restructurer la méthode de recherche et l'approche des phénomènes psychotiques en supprimant l'ontologie cartésienne et du sujet et de l'objet, ce qui suppose le dualisme et le solipsisme de la conscience, pour établir une approche intersubjective de la psychiatrie. Le but de cette recherche est d'examiner précisément le parcours phénoménologique de la Daseinsanalyse psychiatrique de Ludwig Binswanger, plus précisément en ce qui concerne l'accomplissement de ce qu'elle propose, par l'assimilation de la recherche transcendantale dans le domaine des psychoses.

Mots clés: Altérité. phénoménologie. psychiatrie. psychose

(Los fundamentos transcendentales del Daseinsanalyse psiquiátrico de Ludwig Binswanger)

Ludwig Binswanger entendió que era necesario reestructurar el método de investigación y de abordaje de los fenómenos psicóticos, a través del distanciamiento de la ontología cartesiana, del sujeto y el objeto, lo que suponía el dualismo 


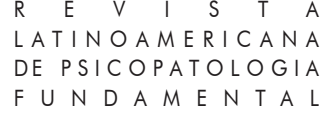

y el solipsismo de la conciencia, para crear un abordaje intersubjetivo de la psiquiatría. El objetivo de esta investigación es examinar el curso fenomenológico del Daseinsanalyse psiquiátrico, de Ludwig Binswanger, en lo que se refiere al cumplimiento de aquello para lo cual se propuso, a través de la asimilación de la investigación trascendental en el campo de las psicosis.

Palabras clave: Alteridad, fenomenología, piquiatría, psicosis

(Die transzendentalen grundlagen der psychiatrischen daseinsanalyse von Ludwig Binswanger)

Ludwig Binswanger verstand es, dass die Restrukturierung der Erforschungsund Erörterungsmethode der psychotischen Phänomene notwendig war, durch die Entfernung der kartesianischen Ontologie des Subjektes und des Objektes, die den Dualismus und den Solipsismus des Gewissens voraussetzten, um einen intersubjektiven Ansatz der Psychiatrie zu gründen. Das Ziel dieser Forschung ist gerade diesen phänomenologischen Verlauf der psychiatrischen Daseinsanalyse von Ludwig Binswanger zu untersuchen, in Bezug auf die erfüllung dessen was sie sich selbst vorgenommen hat, durch die Assimilation der transzendentalen Untersuchung im Bereich de Psychosen.

Key words: Andersartigkeit. Phänomenologie. Psychiatrie. Psychologie.

\section{（路德维希・宾斯汪格精神分析学理论的超越）}

路德维希・宾斯汪格 (Ludwig Binswanger) 认为有必要排除以主体和客体 为中心, 以二元论和唯我意识主义为前提的笛卡尔本体论的影响, 并对精神病 现象的研究方法和途径进行重建, 建立一个超越主观意识的精神病学。本论文 目的是研究路德维希・宾斯汪格精神病理学的现象学分析法, 他的理论的有效性 和连贯性, 以及他在精神病领域所运用的具有先验性的分析方式。

关键词: 他者 (alteridade), 现象学 (fenomenologia), 精神病学, 精神病

Citação/Citation: Alvarenga, R. (2017, junho). Os fundamentos transcendentais da daseins-analyse psiquiátrica de Ludwig Binswanger. Revista Latinoamericana de Psicopatologia Fundamental, 20(2), 368-381. http://dx.doi.org/10.1590/1415-4714.2017v20n2p368.10

Editores do artigo/Editors: Prof. Dr. Claudio E. M. Banzato e Profa. Dra. Rafaela Zorzanelli. 


\section{OBSERVANDO A PSIQUIATRIA}

Recebido/Received: 15.12.2016/ 12.15.2016 Aceito/Accepted: 12.2.2017 / 2.12.2017

Copyright: (C) 2009 Associação Universitária de Pesquisa em Psicopatologia Fundamental/ University Association for Research in Fundamental Psychopathology. Este é um artigo de livre acesso, que permite uso irrestrito, distribuição e reprodução em qualquer meio, desde que o autor e a fonte sejam citados / This is an open-access article, which permits unrestricted use, distribution, and reproduction in any medium, provided the original authors and sources are credited.

Financiamento/Funding: Pesquisa financiada pela Coordenação de Aperfeiçoamento de Pessoal de Nivel Superior - Capes / The research was funded by the Coordenação de Aperfeiçoamento de Pessoal de Nivel Superior - Capes.

Conflito de interesses/Conflict of interest: $\mathrm{O}$ autor declara que não há conflito de interesses / The author has no conflict of interest to declare.

\section{Rodrigo Alvarenga}

Professor de Filosofia da Pontifícia Universidade Católica do Paraná - PUC-PR (Curitiba, PR, Br); Doutor em Filosofia pela Universidade Federal de Santa Catarina - UFSC (Florianópolis, $\mathrm{SC}, \mathrm{Br}$ ).

Pontifícia Universidade Católica do Paraná

R. Imaculada Conceição, 1155 - Prado Velho

80215-901 Curitiba, PR, Br.

alvarenga.rodrigo@pucpr.br

This is an open-access article, which permits unrestricted use, distribution, and reproduction in any medium for non-commercial purposes provided the original authors and sources are credited. 